\title{
The long-term effects of cancer survivorship on household assets
}

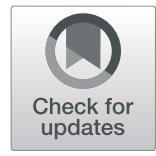

\author{
Tae-Young Pak ${ }^{\text {* }}$ D, Hyungsoo Kim² and Kyoung Tae Kim
}

\begin{abstract}
Background: Less is known about the impact of cancer on household assets and household financial portfolio during which cancer survivors face higher mortality risk. Economic theory predicts that cancer survivors would deplete their wealth in such a way that meets immediate financial needs for treatment and that hedges the risk of anticipated medical expenses associated with recurrence. Building upon this prediction, we examine long-term changes in household assets in response to cancer diagnosis among middle-aged and elderly Americans (age $\geq 50$ ).

Results: Using the 2000-2014 waves of the Health and Retirement Study, we estimated the household fixed effects regression that regresses household assets on time elapsed since cancer diagnosis $(\leq 2$ years, $>2$ but $\leq 4$ years, $>4$ but $\leq 6$ years, and $>6$ but $\leq 8$ years). Regression estimates were adjusted for demographic characteristics, general health condition, employment outcomes, and household economic attributes. Household assets were measured by total net worth as well as the amount of savings held in each asset category. The loss of household assets attributable to cancer was estimated to be $\$ 125,832$ in 2015 dollars per household with a cancer patient. This change came from statistically significant reductions in investment assets, miscellaneous savings, real estate equity, and business equity, and increases in unsecured debt. We also found $17.2-28.0 \%$ increases in cash and cash-equivalent assets from +2 years since diagnosis through the rest of the study periods. The accumulation of cash was observed for both the well-insured group (multiple coverages) and those with limited insurance (single coverage).

Conclusions: The results showed evidence of both asset depletion and precautionary accumulation of liquid assets among cancer survivors, which reduces risk exposure of household financial portfolio. Our findings highlighted that household asset is an important source of liquidity to finance cancer care and to absorb the expected expenditure risk associated with cancer recurrence. We also showed that health insurance provides limited coverage of health risks associated with cancer.
\end{abstract}

Keywords: Cancer treatment, Financial toxicity, Health shock, Asset depletion, Background risk

JEL classification: D14, 110, 131

\section{Background}

The cost of cancer treatments is becoming more expensive with recent developments of immunotherapy and targeted therapeutic approaches [1]. Cancer patients pay a large portion of treatment expenses out-of-pocket (OOP) even with health insurance and suffer from lasting financial toxicity $[2,3]$. Compared with individuals without a cancer history, cancer survivors carry higher medical spending for many years after initial diagnosis due to ongoing cancer care and treatments for comorbidity [4-6]. In addition, cancer incurs

\footnotetext{
*Correspondence: typak@skku.edu

${ }^{1}$ Department of Consumer Sciences, Sungkyunkwan University, Seoul, South Korea

Full list of author information is available at the end of the article
}

indirect monetary losses resulting from missed work days and reduced productivity among patients as well as their caregivers and families $[4,7,8]$. Limitations in work capability often lead to a loss of employer-provided insurance and further magnifies the financial impact of cancer.

Financial distress associated with cancer is likely more severe for older patients. Cancer incidence increases exponentially with age [9], and the prevalence of comorbid conditions makes cancer treatments more costly for the elderly [10]. Although the Medicare and the Affordable Care Act have increased access to health insurance among seniors, OOP expenditures for cancer care have diminished little by these reforms [11]. Once retired, 
pension income (including Social Security) and household assets are the only financial resources that can be used to finance cancer care. Since pension may not provide a sufficient cash flow, household assets would be a primary source of cancer-related expenses for older patients.

Despite a growing scholarly interest in financial toxicity of cancer care, relatively little is known about changes in household balance sheet in response to cancer diagnosis. Household asset is a more inclusive measure of financial consequences, which can capture OOP medical expenses as well as other health-related costs. Gilligan et al. [12], for instance, estimated an average of $\$ 92,098$ reduction in total wealth over 4 years after diagnosis among cancer survivors aged 50 or more. Their estimate was much higher than the previous estimates of lifetime costs, which was in the range of $\$ 40,000$ to $\$ 75$, 000 over a 15-year span [13]. By examining only OOP medical costs and omitting indirect costs and nonhealthcare costs associated with cancer, prior research could have understated the financial cost of cancer. In this study, we propose an alternative approach to infer the adverse financial consequences of cancer from changes in household wealth.

Understanding the effects of cancer on household wealth is important for the following reasons. First, cancer-wealth correlation reflects the cost of cancer care as well as complex financial adjustments and its impact on survivors' quality of life. Cancer patients with limited liquidity and credit constraint were shown to borrow against their primary residence or move out of home [14] and experience a reduction in living standards [15, 16]. They often sacrificed necessities such as clothing, food, and utilities $[17,18]$ and forgone medical care that treats other forms of disease $[19,20]$. The high costs of cancer care and following financial adjustments were associated with poor emotional well-being and a higher risk of depression [21, 22].

Second, by examining the response of asset categories with heterogeneous characteristics, we advance our understanding of how cancer patients manage their financial assets during the post-diagnosis periods. Household assets can be used as a source of treatment expenses as well as a financial buffer against idiosyncratic health risk. A theory of risk-taking suggests that increases in background risk offset willingness to bear other forms of risk [23]. For cancer survivors receiving follow-up medical care, the risk of catastrophic medical expenditures associated with cancer recurrence constitute an important motive of stockpiling liquid financial assets. One way to achieve this adjustment might be to liquidate risky assets to pay off medical bills and keep the unused portion as emergency saving funds. We seek to answer if cancer survivors adjust their portfolio makeup in a manner that hedges the financial risk of cancer recurrence.
This study compared changes in household wealth among cancer survivors to those without a history of cancer using a nationally representative longitudinal data of Americans aged 50 or more. We estimated a dynamic model that separately identifies the immediate and delayed impacts of cancer on household wealth. The results showed that cancer patients experienced about $\$ 125,832$ reduction in total net worth, and that most of this reduction was financed out of investment assets, miscellaneous saving, real estate equity, business equity, and unsecured debt. We also found $17.2-28.0 \%$ increases in liquidity (cash and cash-equivalent assets) since +2 years after diagnosis, which had persisted through the end of the study periods (up to 8 years after onset). Further analysis highlighted that cancer survivors hold additional liquidity even in the presence of health insurance. Our finding contrasts with prior research on household financial fragility that health insurance provides enough financial protection to cancer patients [24-26].

\section{Literature review}

Cancer survivorship is associated with a considerable financial burden on patients. A study of the 2008-2010 Medical Expenditure Panel Survey showed that a newly diagnosed cancer patient (within 1 year) aged 65 or older had an average of $\$ 16,441$ annual total medical expenditures, compared with $\$ 4519$ among previously diagnosed survivors [4]. A study using the cancer registry data linked to Medicare claims estimated monthly cancerattributable costs of $\$ 1100$ for lung cancer patients who received surgery and of $\$ 4809$ for those who were treated with chemotherapy (in 2017 dollars) [27]. The cost estimates typically showed a U-shaped change by the phase of care: related expenses were highest in the initial year of treatment and the last year of life, and lower in the periods in-between [28]. The growth of cancer-related expenses has been leveled off beyond the acute phase but never returned to the pre-diagnosis level [29]. The long-term costs of cancer care (over a 15-year period) ranged from $\$ 65,036$ and $\$ 67,806$ for breast and colon cancer to $\$ 75,554$ for rectal cancer $(\$ 113,615, \$ 118$, 455 , and $\$ 131,991$ in 2018 dollars) [30]. Of the studies that concern total costs of cancer, estimates varied widely across types of treatment, cancer stage and site, population studied, and estimation method $[4,6,28,31]$.

The financial burden of cancer varies with the types and coverage of health insurance. An analysis of the 2010-2014 MarketScan data showed that an average patient with employer-provided plan had incurred about \$7000-\$11,000 OOP expenses over 4 years following diagnosis for a series of care that worths $\$ 100,000-\$ 280$, 000 [29]. A case study from Singleterry [32] illustrated that a patient with colorectal cancer would pay about 
$\$ 1368$ in cost-sharing after having the majority of the total costs $(\$ 123,057)$ covered by Medicare and Medigap plans. In the case of a patient with breast cancer and having employer-sponsored insurance, the OOP burden on a patient is projected to be $\$ 3975$ out of $\$ 144,193$. Evidence from the 2002-2012 waves of the Health and Retirement Study showed that higher OOP costs were associated with less generous health insurance; mean annual OOP spending incurred after a cancer diagnosis were \$2116 among those on Medicaid, \$2367 among those with coverage from the Veterans Health Administration, $\$ 5976$ for those insured by a Medicare health maintenance organization, $\$ 5492$ among those with employer-provided coverage, $\$ 5670$ among those with Medigap, and \$8115 among those with a traditional feefor-service Medicare coverage but without supplemental coverage [33].

Cancer incurs direct medical costs as well as indirect costs resulting from productivity loss. Examples of indirect costs include time spent receiving medical care, time lost from work or other usual activities, lost productivity due to premature death, and lost household productivity for caregiving [34]. A study of cancer survivors in Canada found that the onset of cancer is associated with an average of $10 \%$ reduction in earnings and 5 percentage points decline in the probability of working [35]. The US study using data from the 2008-2011 Medical Expenditure Panel Survey (MEPS) showed that nearly one in three survivors had limitations in usual daily activities outside of work, and one in four felt less productive at work [36]. Among breast cancer survivors, the onset of cancer was associated with a significant increase in absenteeism and disability days [37] in a group with comprehensive health insurance as well as in a group with less coverage [38]. Mean annual indirect costs ranged from a low of $\$ 380$ for patients with prostate cancer [39] to as much as $\$ 16,472$ for patients with breast cancer [37].

Cancer survivors are at risk for financial hardship, as evidenced by the accumulation of medical debt and a higher chance of default. Approximately one-third of cancer survivors reported the use of consumer credits post-treatments, with half of them incurring obligations of $\$ 10,000$ or more [40]. Among breast cancer survivors, $23 \%$ went into debt for treatment-related expenses and held a mean debt of $\$ 26,860$ [41]. Using consumer credits to finance cancer care leaves a long-lasting impact on household balance sheets that persists more than 4 years [14]. Cancer survivors often go bankrupt as a result of their treatment costs. A cancer diagnosis was associated with 2.65 times higher chance of filing for bankruptcy in the state of Washington [42]. Patients with more toxic cancers, such as lung, colorectal, and thyroid cancers, were more likely to declare bankruptcy as compared to those with other types. In a study of US Bankruptcy Court data, medical bankruptcies accounted for more than $50 \%$ of all bankruptcy cases [43]. Besides, several studies noted that a large number of cancer survivors had to cut down spending on basic necessities [44] and exhaust savings to pay medical bills $[3,14,18$, 45].

The financial burden of cancer care expense is associated with psychological distress and subjective ill-being. A study of Hispanic women with breast or gynecological cancer showed that $68 \%$ of them had medical cost concerns, $47 \%$ had wage concerns, and $49 \%$ was subject to financial stress [46]. The cancer survivors with medical cost concerns and worries were more likely to report depressive symptoms and less likely to report positive evaluation of functional, emotional, and physical well-being. The subsequent study by Chino et al. [21] used the patient satisfaction questionnaire and found a significant association between high financial burden and dissatisfaction with general health care, quality of cancer care delivery, and financial aspects of health care. In a study of patients with stage III colorectal cancer, complications after surgery were shown to exacerbate financial burden on patients and increase worry about finances [17].

Beyond quality of life, financial distress has been shown to change decision making regarding treatment. Examples of changes in treatment-related decision making include treatment non-adherence and forgoing/ delaying suggested cancer care. Markman and Luce [47] found that $11 \%$ of cancer patients considered treatment cost when choosing a course of treatments and $9 \%$ forgone the suggested treatment course due to cost-related concerns. Zafar et al. [3] showed that insured cancer patients seeking copayment assistance were more likely to replace suggested medications with over-the-counter drugs in an attempt to reduce OOP expenses. Among cancer survivors faced with financial hardship, about 5-20\% cut spending on medical services unrelated to cancer [19].

A review of the cost estimates for cancer care in the United States found significant heterogeneity across the types of tumor, baseline data, study methods, and population studied [13]. Sources of cost data included insurance claims, medical bills, hospital discharge data, and self-reports [28, 34]. The limitation of the prior approach is that (a) calculation of indirect costs builds upon strong assumptions, and (b) existing insurance claim data does not provide information on those not having health insurance. The alternative approach, which has been followed in some prior research, is to infer the cost of cancer diagnosis from changes in household assets before and after diagnosis. For instance, Lee and Kim [48] examined the impact of new health events and existing health conditions on wealth depletion in later life. Kim and Lee [49] linked compounded health 
problems to wealth changes and found that wealth depletion was most pronounced for those with a combination of heart disease and diabetes. Similar approaches have been used in Spicer et al. [50], Poterba et al. [26], and $\mathrm{Wu}$ [51]. Our study extends this line of research by estimating long-term changes in wealth following a cancer diagnosis.

\section{Methods}

\section{Data description}

The sample is drawn from the 2000-2014 waves of the Health and Retirement Study (HRS). The HRS is a nationally representative survey of the noninstitutionalized population aged 50 years and older and their spouses [52]. The survey has been fielded every other year since 1992 with a goal of tracking lifestyle changes of American seniors. Information collected ranges from demographic, socioeconomic, and health characteristics of individual respondents to their household assets and income.

We apply the following sample selection criteria. First, we eliminate respondents younger than age 50 from the sample. Individuals dropped at this stage are predominantly female spouses who are included in the study as a spouse of the age-eligible householder. Second, we drop the Mid Baby Boomer cohort (born in 1954-1959). This cohort has been tracked only for three waves and does not provide enough observations for panel data analysis with lagged regressors. Third, we delete households in which one or more spouses died from cancer or those reported multiple cancer diagnoses during the study period. These groups would exhibit a different pattern of asset depletion for reasons unrelated to cancer, such as bequest and donation at the end of life, and confound regression estimates for the cancer effect. Lastly, we delete respondents with only one observation in order for our estimation strategy to exploit within-person variations. The final sample is an unbalanced panel of 68 , 634 observations for 16,451 respondents (1354 cancer survivors and 15,097 individuals without a history of cancer) and 10,933 households.

\section{Measures of household assets}

The HRS gathered information on household wealth and income through the survey of a financial respondent in each household. Our summary measure of household wealth is total net worth - the sum of cash and cashequivalent assets, stocks, bonds, miscellaneous savings, retirement savings, housing, vehicles, real estate, and private business, minus unsecured debt. All monetary values are converted to 2015 dollars using the consumer price index for all urban consumers (CPI-U).

While aggregate measures show overall changes in household assets, they would not reveal the different pattern of depletion in assets with heterogeneous characteristics. For instance, cancer patients may use liquid assets for treatments in the acute phase and exhaust non-financial assets, such as residence and real estate, for subsequent treatments. Some patients would reallocate their illiquid assets to cash and cash-equivalents to cope with a chance of catastrophic medical expenses associated with recurrent cancer. To examine these channels, in the second phase of analysis we examine the following asset categories separately: (a) cash and cashequivalents, (b) stocks and bonds, (c) miscellaneous savings, (d) individual retirement accounts, (e) housing equity, (f) vehicles, (g) real estate equity, (h) private business, and (i) unsecured debt. The detailed description of asset variables is presented in Table 1.

\section{Measure of cancer diagnosis}

Respondents with a newly diagnosed cancer are identified through the following survey question, "Since the previous interview, has a doctor ever told you that you have cancer or a malignant tumor, excluding minor skin cancers?." Responses to this question are converted to a household-level cancer indicator, which takes on one for households with a spouse newly diagnosed with cancer and zero otherwise. The fraction of married couples with cancer diagnosis ranges from 3.0 to $3.8 \%$ of the sample in each survey wave. Approximately $8.2 \%$ of our final sample exhibit a history of cancer diagnosis during the study period.

\section{Empirical specification}

The regression model for household $i$ in time period $t$ takes the following form,

$$
\begin{aligned}
y_{i t}= & \psi+\beta_{0} c_{i t}+\beta_{1} c_{i t-1}+\beta_{2} c_{i t-2}+\beta_{3} c_{i t-3}+X_{i t} \lambda+v_{i} \\
& +v_{t}+\varepsilon_{i t},(1)
\end{aligned}
$$

where $y_{i t}$ is a measure of household asset, $c_{i t}$ is binary indicator for cancer onset between period $t-1$ and $t$; $X_{i t}$ is a vector of covariates; and $v_{t}$ is a common time trend in wealth outcome (e.g., business cycle) that will be captured by year-of-survey dummies. All regressions include three lags of the cancer indicator $\left(c_{i t-1}, c_{i t-2}\right.$, and $\left.c_{i t-3}\right)$ to capture the lasting effects of cancer on household assets. ${ }^{1}$ Since we include lagged regressors, the outcome variable and covariates $\left(y_{i t}, X_{i t}\right.$, and $\left.v_{t}\right)$ are based on five survey waves from 2006 to 2014.

The error term consists of the i.i.d. random error $\left(\varepsilon_{i t}\right)$ and a household-specific time-invariant factor that captures unobserved household heterogeneity $\left(v_{i}\right)$. To account for the potential confounding effects of $v_{i}$, we

\footnotetext{
${ }^{1}$ The preliminary analysis shows that the effect of cancer on wealth does not persist beyond three survey periods. Therefore, the maximum lag length of cancer is three.
} 
Table 1 Measures of household asset

\begin{tabular}{ll}
\hline & Definition \\
\hline Cash and cash equivalents & Checking accounts, savings accounts, money market accounts, CD, government savings bonds, and T-bills \\
Btocks & Stocks, mutual funds, and investment trusts \\
Miscellaneous savings & Bonds and bond funds \\
Retirement savings & Jewelry, money owed by others, a collection for investment purposes, rights in a trust or estate, or an annuity \\
Housing equity & IRA and Keogh accounts (net value) \\
Vehicles & Primary and secondary residence (net value) \\
Real estate equity & All vehicles owned by a household (net value) \\
Business equity & Real estate other than home (net value) \\
Unsecured debts & Private farm or business (net value) \\
\hline
\end{tabular}

estimate a household fixed effects (FE) model. This approach differences out $v_{i}$ and uses only the withinhousehold variation to estimate regression parameters. The parameters of interest $\left(\beta_{0}, \beta_{1}, \beta_{2}\right.$, and $\left.\beta_{3}\right)$ capture between-survey changes in household wealth due to the onset of cancer in the current and previous periods.

A covariate vector $X_{i t}$ includes time-varying characteristics of respondents or households that might be correlated with household assets. These variables include age and age squared, marital status, number of children, self-rated physical health, labor force participation, health insurance ownership, annual household income, transfer of financial resources between adult children and respondents, and Census division of residence. The age effect is modeled in a quadratic form to allow household wealth decumulate at an increasing rate over age. Respondents' overall health condition is captured by a five-category self-rated health (poor, fair, good, very good, and excellent). For marital status, we include dummies for married, divorced or separated, and widowed in reference to never-married. Labor force participation is categorized into fully employed, partially employed, unemployed, retired, and not in the labor force. Health insurance coverage is coded with three exclusive categories: (a) no insurance, (b) single health insurance coverage or two or more government-provided plans (Medicaid, Medicare, both Medicaid and Medicare, veteran's insurance, a single private plan, or coverage through spouse's plan), and (c) multiple health insurance coverages or employer-provided plan.

To account for high skewness in outcome variables, the income and wealth variables (household asset, household income, and intergenerational transfers) are transformed by the log-modulus transformation [53]. This transformation takes a $\log$ on the absolute value of $y_{i t}$ plus 1 and multiplies this quantity by -1 if the original value is negative. The formula can be expressed as, $\operatorname{sign}\left(y_{i t}\right) \cdot \log (|x|+1)$. This approach has advantages over a naïve log-transformation in that it preserves the location of zero values and spread out negative values across the same logarithmic scale on a negative domain. Interpretation of marginal effects remains unchanged.

\section{Results}

Table 2 presents average descriptive statistics for the full sample and separately for a non-cancer group and a cancer survivor group. The last three columns present cancer survivors' characteristic for pre-diagnosis, initial phase of treatment ( $\leq 2$ years after diagnosis), and continuing phase of treatment ( $>2$ years after diagnosis). The sample is about 69.6 years old, $58.7 \%$ female, and $65.3 \%$ married. Approximately $92.4 \%$ reported one or more health insurance coverage (including Medicaid and Medicare), and $70.9 \%$ assessed their overall health good or better. Comparing respondents by cancer history shows that cancer has been more prevalent in males (46.6\% vs $40.5 \% ; P<.01$ ), older respondents $(70.0$ vs $69.5 ; P<.01)$, retirees $(71.4 \%$ vs $64.8 \% ; P<.01)$, and households with more assets ( $\$ 595,873$ vs $\$ 524,858$; $P<.01)$ and income $(\$ 72,024$ vs $\$ 69,586 ; P<.01)$. The mean total net worth was reduced from a pre-diagnosis average of $\$ 659,537$ to $\$ 608,993$ in the initial phase and to $\$ 515,604$ in the continuing phase. The liquidation pattern is more pronounced for non-housing illiquid assets, such as real estate equity and business equity. The amount held in cash and cash-equivalent assets is higher in the continuing phase, relative to the initial phase $(\$ 58$, 477 vs $\$ 54,078 ; P<.01)$.

Table 3 presents estimates from the regression of total net worth on cancer and covariates. We first estimate a null model (column 1) and then add additional controls to evaluate the robustness of our results (columns 2 and 3).

All three columns show that the onset of cancer was followed by immediate reductions in total net worth. The coefficient estimates on cancer at $t-1$ carry a negative sign and reject the null hypothesis of nonsignificance at the $1 \%$ level. In our preferred specification (column 3), the coefficient estimate on the 
Table 2 Average descriptive statistics

\begin{tabular}{|c|c|c|c|c|c|c|}
\hline & $\begin{array}{l}\text { Full } \\
\text { sample } \\
(N=68,634)\end{array}$ & $\begin{array}{l}\text { No history of cancer } \\
(N=58,593)\end{array}$ & $\begin{array}{l}\text { Cancer survivor } \\
(N=10,041)\end{array}$ & $\begin{array}{l}\text { Before diagnosis } \\
(N=4121)\end{array}$ & $\begin{array}{l}\text { Initial } \\
\text { phase } \\
(N=2279)\end{array}$ & $\begin{array}{l}\text { Continuing phase } \\
(N=3641)\end{array}$ \\
\hline \multicolumn{7}{|l|}{ Individual characteristics } \\
\hline Age & 69.6 & 69.5 & 70.0 & & & \\
\hline Female $^{a}$ & 58.7 & 59.5 & 53.4 & & & \\
\hline Married $^{a}$ & 65.3 & 63.2 & 77.8 & & & \\
\hline Separated or divorced ${ }^{\mathrm{a}}$ & 12.6 & 13.3 & 8.5 & & & \\
\hline Widowed $^{a}$ & 18.5 & 19.6 & 12.0 & & & \\
\hline Never married ${ }^{a}$ & 3.5 & 3.8 & 1.8 & & & \\
\hline Number of children & 3.2 & 3.2 & 3.2 & & & \\
\hline Self-rated health: good or better ${ }^{\mathrm{a}}$ & 70.9 & 71.1 & 70.0 & & & \\
\hline No health insurance ${ }^{a}$ & 7.6 & 8.0 & 5.6 & & & \\
\hline Single health insurance ${ }^{a}$ & 46.2 & 46.6 & 43.7 & & & \\
\hline Multiple health insurance ${ }^{a}$ & 46.2 & 45.4 & 50.8 & & & \\
\hline Fully employed ${ }^{a}$ & 20.2 & 20.7 & 17.0 & & & \\
\hline Partially employed ${ }^{a}$ & 4.5 & 4.7 & 3.3 & & & \\
\hline Unemployed $^{a}$ & 1.8 & 1.8 & 1.5 & & & \\
\hline Retired $^{a}$ & 65.8 & 64.8 & 71.4 & & & \\
\hline Not in the labor force ${ }^{a}$ & 7.7 & 7.9 & 6.7 & & & \\
\hline \multicolumn{7}{|l|}{ Household income and wealth ${ }^{b}$} \\
\hline Total income & 69,943 & 69,586 & 72,024 & 80,919 & 71,599 & 62,222 \\
\hline Total net worth & 535,247 & 524,858 & 595,873 & 659,537 & 608,993 & 515,604 \\
\hline Cash and cash equivalents & 49,987 & 48,764 & 57,124 & 57,613 & 54,078 & 58,477 \\
\hline Stocks and bonds & 88,705 & 90,327 & 79,240 & 84,887 & 79,624 & 72,609 \\
\hline Miscellaneous savings & 14,845 & 14,091 & 19,240 & 23,623 & 17,917 & 15,109 \\
\hline Retirement savings & 79,319 & 76,675 & 94,749 & 96,936 & 96,191 & 91,372 \\
\hline Housing equity & 184,538 & 180,423 & 208,555 & 223,915 & 204,507 & 193,702 \\
\hline Vehicles & 16,693 & 16,349 & 18,702 & 20,035 & 18,023 & 17,617 \\
\hline Real estate equity & 53,127 & 52,553 & 56,475 & 69,481 & 66,706 & 35,351 \\
\hline Business equity & 52,970 & 50,544 & 67,128 & 89,373 & 78,155 & 35,049 \\
\hline Unsecured debts & 4938 & 4869 & 5340 & 6325 & 6208 & 3681 \\
\hline
\end{tabular}

Initial phase represents the first HRS survey followed by a cancer diagnosis ( $\leq 2$ years after diagnosis). Continuing phase represents all subsequent periods after the initial phase ( $>2$ years but $\leq 8$ years after diagnosis)

andividual characteristics (excluding age and number of children) represent percentage figures

${ }^{\mathrm{b}}$ Household income and wealth are adjusted to 2015 dollars using the Consumer Price Index for all urban consumers

immediate cancer effect is -0.268 , with a $95 \%$ CI ranging from -0.439 to -0.097 . This estimate corresponds to a $23.5 \%\left(=1-e^{-0.268}\right)$ reduction or a $\$ 125,832$ loss $\left(=\$ 535,247 \times\left(1-e^{-0.268}\right)\right)$ in total net worth, evaluated at the sample mean. The estimated cancer effects for the subsequent periods maintain a negative sign but are not different from zero at the $5 \%$ level. In all specifications, asset depletion is more pronounced for the acute phase of treatment. Coefficient estimates for the covariates show that household assets increase with being married, self-reported health, health insurance, and total income, but decreases with cancer diagnosis.
Table 4 presents estimates for associations between cancer diagnosis and the amounts held in each asset category. Regressions control for all explanatory variables, including year-of-survey fixed effects and Census division dummies. The estimates for covariates are omitted for brevity.

The results show the evidence of both (a) asset depletion to meet immediate financial needs and (b) risk hedging to cope with the risk of recurrent cancer. Three results stand out. First, the cost of cancer was financed out of savings held in risky assets $\left(\beta_{0}=-0.170,95 \% \mathrm{CI}\right.$ : -0.328 to $-0.012, P<0.05)$, miscellaneous saving $\left(\beta_{0}=\right.$ 
Table 3 Cancer effects on household wealth $(N=68,634)$

\begin{tabular}{|c|c|c|c|}
\hline \multirow[t]{2}{*}{ Response: } & $\begin{array}{l}\text { Log } \\
\text { (Total NW) }\end{array}$ & $\begin{array}{l}\text { Log } \\
\text { (Total NW) }\end{array}$ & $\begin{array}{l}\text { Log } \\
\text { (Total NW) }\end{array}$ \\
\hline & (1) & (2) & (3) \\
\hline \multirow[t]{2}{*}{$\beta_{0}:$ Cancer $t$} & $-0.260^{* * *}$ & $-0.288^{* * *}$ & $-0.268^{* * *}$ \\
\hline & $(0.088)$ & $(0.087)$ & $(0.087)$ \\
\hline \multirow[t]{2}{*}{$\beta_{1}$ : Cancer $t-1$} & -0.152 & $-0.179^{*}$ & $-0.173^{*}$ \\
\hline & $(0.094)$ & $(0.094)$ & $(0.094)$ \\
\hline \multirow[t]{2}{*}{$\beta_{2}:$ Cancer $t-2$} & -0.132 & -0.141 & -0.143 \\
\hline & $(0.088)$ & $(0.088)$ & $(0.088)$ \\
\hline \multirow[t]{2}{*}{$\beta_{3}:$ Cancer $t-3$} & -0.151 & $-0.158^{*}$ & $-0.154^{*}$ \\
\hline & $(0.093)$ & $(0.093)$ & $(0.093)$ \\
\hline \multirow[t]{2}{*}{ Age } & & $0.169^{* * *}$ & $0.148^{* * *}$ \\
\hline & & $(0.033)$ & $(0.033)$ \\
\hline \multirow[t]{2}{*}{ Age squared (/100) } & & $-0.109^{* * *}$ & $-0.094^{* * *}$ \\
\hline & & $(0.023)$ & $(0.023)$ \\
\hline \multirow[t]{2}{*}{ Married } & & $1.089^{* * *}$ & $1.011^{* * *}$ \\
\hline & & $(0.324)$ & $(0.322)$ \\
\hline \multirow[t]{2}{*}{ Separated or divorced } & & -0.429 & -0.411 \\
\hline & & $(0.331)$ & $(0.330)$ \\
\hline \multirow[t]{2}{*}{ Widowed } & & 0.517 & 0.487 \\
\hline & & $(0.324)$ & $(0.323)$ \\
\hline \multirow[t]{2}{*}{ Number of children } & & -0.020 & -0.021 \\
\hline & & $(0.042)$ & $(0.042)$ \\
\hline \multirow[t]{2}{*}{ SR health: fair } & & & $0.358^{* * *}$ \\
\hline & & & $(0.081)$ \\
\hline \multirow[t]{2}{*}{ SR health: good } & & & $0.408^{* * *}$ \\
\hline & & & $(0.080)$ \\
\hline \multirow[t]{2}{*}{ SR health: very good } & & & $0.457^{* * *}$ \\
\hline & & & $(0.083)$ \\
\hline \multirow[t]{2}{*}{ SR health: excellent } & & & $0.523^{* * *}$ \\
\hline & & & $(0.093)$ \\
\hline \multirow[t]{2}{*}{ Single health insurance } & & & 0.108 \\
\hline & & & $(0.109)$ \\
\hline \multirow[t]{2}{*}{ Multiple health insurance } & & & $0.273^{* *}$ \\
\hline & & & $(0.110)$ \\
\hline \multirow[t]{2}{*}{ Fully employed } & & & -0.070 \\
\hline & & & $(0.089)$ \\
\hline \multirow[t]{2}{*}{ Partially employed } & & & 0.080 \\
\hline & & & $(0.114)$ \\
\hline \multirow[t]{2}{*}{ Unemployed } & & & -0.194 \\
\hline & & & $(0.176)$ \\
\hline \multirow[t]{2}{*}{ Retired } & & & 0.048 \\
\hline & & & $(0.072)$ \\
\hline \multirow[t]{2}{*}{$\log (\mathrm{HH}$ income $)$} & & & $0.141^{* * *}$ \\
\hline & & & $(0.021)$ \\
\hline
\end{tabular}

Robust standard errors in parentheses. Subscript $t-1, t-2$, and $t-3$ represent variables measured in one, two, and three survey periods earlier $(2,4$, and 6 years prior to the measurement of wealth). Total NW represents total net worth. Regressions control for the log of intergenerational transfers, year-ofsurvey dummies, and Census division fixed effects. ${ }^{* * *} p<0.01$; ${ }^{* *} p<0.05$; ${ }^{*} p<0.10$
- 0.163, 95\% CI: -0.311 to $-0.016, P<0.05)$, real estate equity $\left(\beta_{0}=-0.167,95 \% \mathrm{CI}:-0.298\right.$ to $-0.035, P<$ $0.05)$, and business equity $\left(\beta_{1}=-0.145,95 \% \mathrm{CI}:-0.265\right.$ to $-0.025, P<0.05$; and $\beta_{2}=-0.175,95 \% \mathrm{CI}:-0.297$ to $-0.052, P<0.01)$. The onset of diagnosis was associated with immediate liquidation of risky assets, miscellaneous saving, and real estate equity, and was followed by an additional decrease in risky assets and business equity through the continuing phase. Second, cancer survivors held additional liquidity after the treatment $\left(\beta_{1}=0.247\right.$, 95\% CI: 0.126 to $0.367, P<0.01 ; \beta_{2}=0.184,95 \% \mathrm{CI}$ : 0.051 to $0.317, P<0.01$; and $\beta_{3}=0.159,95 \% \mathrm{CI}$ : 0.017 to 0.301, $P<0.05)$. The marginal effect interpretation and back-of-the-envelope calculation using sample means show that household savings held in cash and cashequivalents increased by $17.2-28.0 \%$, or by $\$ 8615-\$ 14$, 005 from year +2 to year +8 since diagnosis. Given the magnitude of these estimates compared to those on risky assets and business equity, it is plausible to say that a portion of liquidated assets not spent on cancer care has been held as additional cash. Third, cancer accompanies a large increase in unsecured debts. The coefficient estimates on cancer range from 0.170 to 0.282 and reject the null hypothesis of non-significance at the 5\% level across all post-cancer periods. Our rough estimate of additional liability due to cancer is $\$ 1314$ in the acute phase, and is in the range of $\$ 915-\$ 1609$ for the continuing phase. The debt load peaks around year +2 through year +4 and remains significant throughout the post-cancer periods. Although there is no way to confirm if these estimates came from refinancing of the existing loan or the initial loan carried into the next periods, they all point to the lasting effects of cancer on household liabilities.

The relatively novel finding is that cancer patients reallocate their wealth from risky assets to the liquid form of savings. The primary motivation of this adjustment might be that insurance coverage does not provide enough financial protection against catastrophic medical expenditures. If health insurance fully indemnifies expected medical expenditures, cancer survivors would not show cash-stocking behaviors after diagnosis. To test for this argument, we examine if health insurance coverage moderates the association between cancer onset and household assets. Our empirical strategy is to interact cancer indicators with a dummy for having multiple coverages or employer-provided insurance $(1=$ multiple health insurance coverages or employer-provided plan; $0=$ no health insurance or single coverage including government-provided insurance) and examine linear restrictions on the interaction terms. Table 5 presents the related results. Overall, our estimates show the evidence of asset depletion and risk hedging through portfolio relocation towards cash in both groups. 
Table 4 Cancer effects on household wealth, by asset categories $(N=68,634)$

\begin{tabular}{|c|c|c|c|c|c|c|c|c|c|}
\hline Response: & $\begin{array}{l}\text { Log } \\
\text { (cash) } \\
(1)\end{array}$ & $\begin{array}{l}\text { Log } \\
\text { (stocks+bonds) } \\
(2)\end{array}$ & $\begin{array}{l}\text { Log } \\
\text { (miscellaneous) } \\
\text { (3) }\end{array}$ & $\begin{array}{l}\text { Log } \\
\text { (retirement) } \\
\text { (4) }\end{array}$ & $\begin{array}{l}\text { Log } \\
\text { (housing) } \\
\text { (5) }\end{array}$ & $\begin{array}{l}\text { Log } \\
\text { (vehicles) } \\
\text { (6) }\end{array}$ & $\begin{array}{l}\text { Log } \\
\text { (estate) } \\
(7)\end{array}$ & $\begin{array}{l}\text { Log } \\
\text { (business) } \\
(8)\end{array}$ & $\begin{array}{l}\text { Log } \\
\text { (unsecured debt) } \\
\text { (9) }\end{array}$ \\
\hline \multirow[t]{2}{*}{$\overline{\beta_{0}: \text { Cancer } t}$} & -0.021 & $-0.170^{* *}$ & $-0.163^{* *}$ & 0.002 & -0.063 & 0.017 & $-0.167^{* *}$ & -0.078 & $0.236^{* * *}$ \\
\hline & $(0.059)$ & $(0.081)$ & $(0.075)$ & $(0.074)$ & $(0.087)$ & $(0.052)$ & $(0.067)$ & $(0.055)$ & $(0.076)$ \\
\hline \multirow[t]{2}{*}{$\beta_{1}$ : Cancer $t-1$} & $0.247^{* * *}$ & $-0.369^{* * *}$ & 0.002 & 0.020 & -0.075 & 0.012 & -0.072 & $-0.145^{* *}$ & $0.282^{* * *}$ \\
\hline & $(0.061)$ & $(0.087)$ & $(0.087)$ & $(0.081)$ & $(0.096)$ & $(0.060)$ & $(0.075)$ & $(0.061)$ & $(0.081)$ \\
\hline \multirow[t]{2}{*}{$\beta_{2}$ : Cancer $t-2$} & $0.184^{* * *}$ & $-0.401^{* * *}$ & -0.017 & -0.075 & -0.053 & 0.017 & 0.008 & $-0.175^{* * *}$ & $0.171^{* *}$ \\
\hline & $(0.068)$ & $(0.092)$ & $(0.090)$ & $(0.088)$ & $(0.094)$ & $(0.061)$ & $(0.078)$ & $(0.063)$ & $(0.082)$ \\
\hline \multirow[t]{2}{*}{$\beta_{3}:$ Cancer $t-3$} & $0.159^{* *}$ & -0.058 & $-0.175^{*}$ & -0.028 & -0.066 & $0.123^{*}$ & -0.114 & -0.011 & $0.170^{* *}$ \\
\hline & $(0.073)$ & $(0.090)$ & $(0.090)$ & $(0.092)$ & $(0.092)$ & $(0.064)$ & $(0.076)$ & $(0.063)$ & $(0.081)$ \\
\hline
\end{tabular}

Robust standard errors in parentheses. Subscript $t-1, t-2$, and $t-3$ represent variables measured in one, two, and three survey periods earlier $(2,4$, and 6 years prior to the measurement of wealth). Regressions control for a full set of covariates, including year and Census division fixed effects. ${ }^{* * *} p<0.01 ;{ }^{* *} p<0.05 ;{ }^{*} p<0.10$

Table 5 Cancer effects on household wealth, by asset categories and insurance coverage $(N=68,634)$

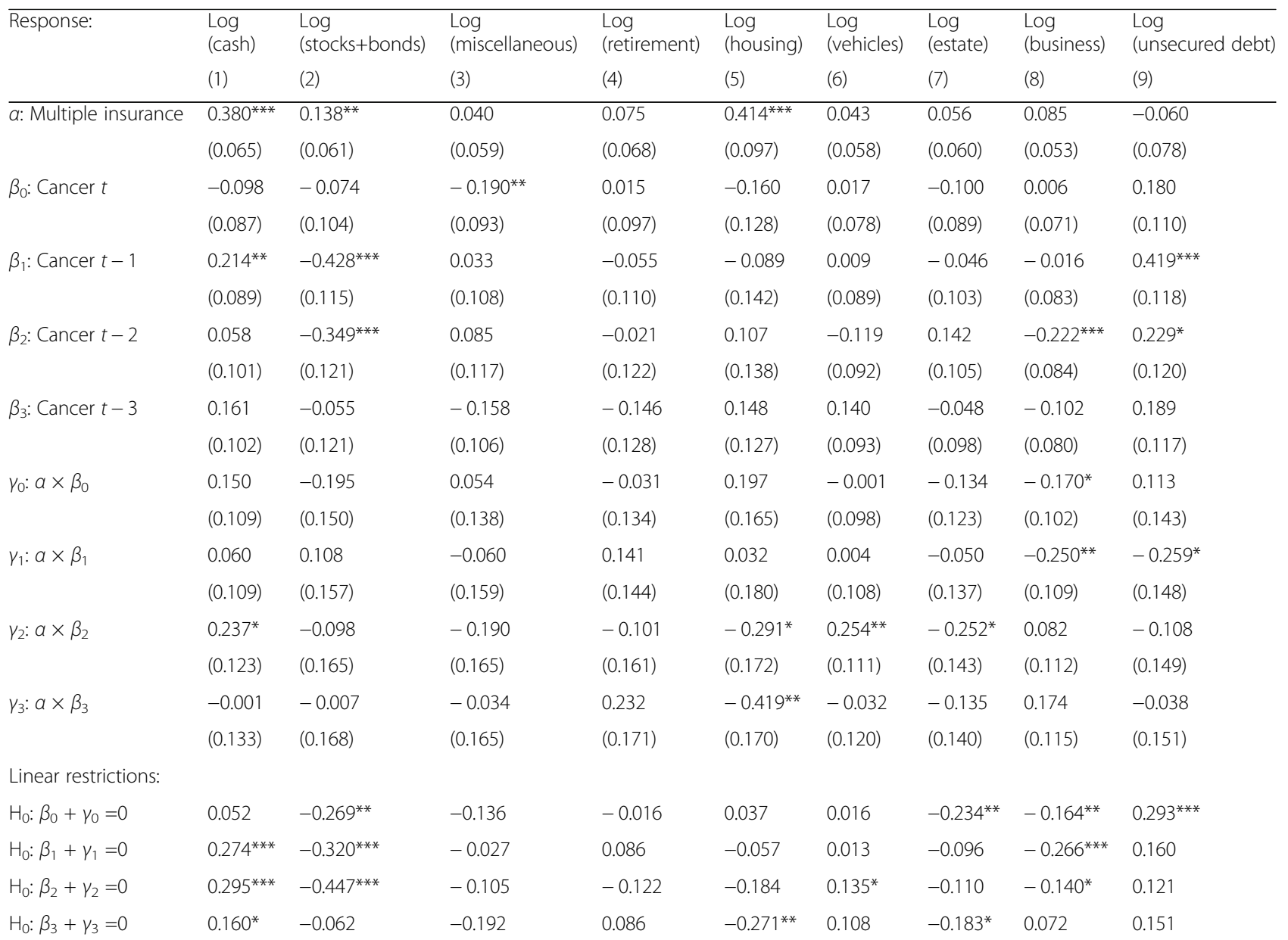




\section{Discussion}

This study showed that household assets serve as a financial buffer against cancer care expenses as well as a higher financial risk associated with cancer recurrence. We found that cancer diagnosis was followed by significant reductions in investment asset, miscellaneous saving, real estate equity, and business equity, and modest increases in cash and cash-equivalent assets and unsecured debt, which is equivalent to an average of $\$ 125$, 832 (in 2015 dollars) net reduction in total net worth. We also found that additional cash holding emerged 2 years after the diagnosis and remained significant until the end of our tracking periods (year +8 since the diagnosis). A similar pattern of asset depletion was observed for groups with limited health insurance coverage as well as those having multiple health insurance. Overall, cancer patients in our study exhibit portfolio reallocation towards low-risk and liquid assets and the evidence of precautionary saving in periods during which the risk of cancer recurrence is high (year +2 through year +8 ).

Our results show three notable findings. First, our estimate of asset depletion due to cancer was significantly larger than the previous estimates of OOP spending on cancer care. This difference can be explained by the fact that household wealth is a more inclusive measure of financial cost, which captures both direct costs and indirect economic burden on family members who would have forgone productive activities for caregiving. Our finding then indicates that using direct spending on cancer care would vastly understate the economic burden of cancer on patients and their family members.

Second, cancer survivors reallocated their savings portfolio away from risky equities and towards liquid assets that carry little or no financial risk. We found that cancer survivors held much less in risky assets, such as stocks and bonds, real estate equity, and business equity, but carried additional cash throughout the continuing phase of treatment. This pattern of portfolio reallocation was consistent with the background risky theory that increases in background risk offset willingness to bear other forms of risk [23]. Background risk is uninsurable, independent from financial risk, and not avoidable through diversification of asset portfolio [54, 55]. Heath risk is considered to be a typical example of background risk [56]. The onset of cancer is largely unpredictable and beyond one's control; all else being equal, cancer patients face a higher risk of catastrophic medical spending than those in good health. Knowing the financial toxicity of cancer care from their experiences with an initial occurrence, cancer survivors have an incentive to reduce exposure to financial risk and accumulate additional liquidity to safeguard against the expected financial burden when tumor returns. A recent longitudinal study of American elderly reported a similar coping strategy that associates cancer with a draw-down of risky assets and increases in an emergency fund [57].

Third, having additional health insurance had a limited impact on the extent to which households with cancer patients deplete their wealth and using cash as a financial buffer. The substitution between financial risk and health risk is more pronounced for a sample we believe to be well-insured (through either employer-provided plan or multiple health insurance coverages not including Medicare + Medicare), compared with a less insured group (single coverage or coverages only from public insurance). These findings suggest that insurance policies that cover only the costs of medical care are likely to provide only partial protection against the full cost of cancer. As noted in the cost estimates, current public and private health insurance programs are insufficient to fully prevent financial distress resulting from various forms of indirect costs.

\section{Limitations}

This study has a number of limitations. First, our analysis is subject to survivorship bias resulting from mortality differential across pathologic stages. The lower life expectancy for toxic tumors raises the concern that patients with advanced cancer or certain types that have low survival rates are under-represented in the sample and those with curable types are over-represented. Since treatment costs are higher for advanced cancers [58], our estimates of wealth effect might be biased downwards. Second, the cancer screening question in the HRS excludes skin cancer and non-malignant tumors. It is possible that those with skin cancer or non-malignant tumors were assigned to the non-cancer group, and this measurement error led to a smaller difference in wealth by cancer history. Third, the estimates could be confounded by voluntary changes in consumption behaviors. The onset of cancer could have reduced non-health consumption by limiting mobility, travel opportunities, and the ability to consume food away from home. At the same time, it could motivate patients to consume "before it's too late" and results in a higher rate of spending in anticipation of survival risk [26]. These two forces can either amplify or weaken cancer-wealth correlation depending on which channel carries a larger effect. Fourth, debt accumulation post-cancer could be the manifestations of strategic considerations by patients. For instance, patients with only a few years to live may increase debts and choose to strategically default on them [59]. If then, changes in liabilities are determined by catastrophic medical expenses as well as a lack of intention to repay debts. Due to the limitations in data, we are unable to test this motive and its impact on the estimated cancer effect. 


\section{Conclusions}

Our cost estimate suggests that middle-aged and elderly Americans need to take into account the potential medical costs associated with cancer onset in retirement planning. An important implication of wealth depletion following a cancer diagnosis is that senior households are not holding enough financial buffer to cope with medical expenses. The onset of cancer can be particularly detrimental to older adults due to limited income sources after retirement and a higher risk of complications associated with cancer treatment. In particular, patients with more toxic cancers are at higher risk for costly health and financial consequences. Financial advisors and practitioners are encouraged to use our findings to advise clients with a family cancer history on how much emergency saving to hold and how to allocate household assets.

Our finding on the depletion pattern across insurance coverage supports further expansion of Medicare. We observed reallocation of household wealth towards liquid assets for both well-insured and under-insured groups, implying that cancer patients found financial protection through health insurance inadequate. These results are consistent with the recent finding that a third of insured cancer patients pay more expenses out-of-pocket than they expected, despite having health coverage [60]. Medicare program needs to pick up more co-payments associated with curative care and expand coverage to homebased long term care and palliative care, which are not included in the current benefit category. Besides, individuals with a family history of toxic tumors may want to consider a private cancer insurance policy to offset the anticipated financial consequence of cancer diagnosis.

Given the rising cost of new cancer therapies, there has been considerable interest in the relationship between cancer-related treatment expenses and mortality outcomes post-treatment [11]. A study of the 19962004 HRS estimated that older persons with one or more financial hardships have 1.4-1.8 times higher hazard ratios than those without financial difficulties [61]. The financial distress from mounting financial obligations and debt is a major risk factor for mortality after cancer diagnosis [62]. The depletion of wealth may come with greater emotional distress for older patients due to limited labor income after retirement. A possible direction of future research is to examine how asset depletion for cancer care affects mortality risk and quality of life among cancer survivors.

\section{Abbreviations}

CPI-U: Consumer price index for all urban consumers (CPI-U); HRS: Health and Retirement Study; MEPS: Medical Expenditure Panel Survey; OOP: Out-ofpocket

\section{Authors' contributions}

TYP conceptualized the study, performed data analyses, and drafted the manuscript. HK conceived the theoretical framework, supervised data analyses and interpretation, and drafted the manuscript. KTK contributed to the research design and implementation, and participated in the manuscript draft and revision. TYP takes responsibility for the integrity of data handling and accuracy of the statistical analyses. All authors provided critical

feedbacks and approved the final manuscript.

\section{Funding}

This research did not receive any specific grant from funding agencies in the public, commercial, or not-for-profit sectors. The HRS is sponsored by the National Institute on Aging (grant number: NIA U01AG009740) and is conducted by the University of Michigan.

\section{Availability of data and materials}

The datasets of the current study are publicly available at the Health and Retirement Study data portal (https://hrs.isr.umich.edu/data-products/accessto-public-data). The computer codes that convert the original data to estimates are available from the corresponding author on reasonable request.

Ethics approval and consent to participate

Not applicable.

\section{Consent for publication}

Not applicable.

\section{Competing interests}

The authors declare that they have no conflict of interest.

\section{Author details}

'Department of Consumer Sciences, Sungkyunkwan University, Seoul, South Korea. 'Department of Family Sciences, University of Kentucky, Lexington, KY, US. ${ }^{3}$ Department of Consumer Sciences, University of Alabama, Tuscaloosa, $A L, U S$.

Received: 20 June 2019 Accepted: 4 December 2019

Published online: 13 January 2020

\section{References}

1. Bach PB. Limits on Medicare's ability to control rising spending on cancer drugs. N Engl J Med. 2009:360(6):626-33.

2. Altice CK, Banegas MP, Tucker-Seeley RD, Yabroff KR. Financial hardships experienced by cancer survivors: a systematic review. J Natl Cancer Inst. 2017;109(2):djw205.

3. Zafar SY, Peppercorn JM, Schrag D, Taylor DH, Goetzinger AM, Zhong X et al. The financial toxicity of cancer treatment: a pilot study assessing outof-pocket expenses and the insured cancer patient's experience. Oncologist. 2013;18(4):381-90

4. Guy GP, Ekwueme DU, Yabroff KR, Dowling EC, Li C, Rodriguez $J$, et al. Economic burden of cancer survivorship among adults in the United States. J Clin Oncol. 2013;31(30):3749-57.

5. Short PF, Moran JR, Punekar R. Medical expenditures of adult cancer survivors aged $<65$ years in the United States. Cancer. 2011;117(12):2791-800.

6. Yabroff KR, Lamont EB, Mariotto A, Warren JL, Topor M, Meekins A, et al. Cost of care for elderly cancer patients in the United States. J Natl Cancer Inst. 2008;100(9):630-41.

7. Wranik WD, Muir A, Hu M. Costs of productivity loss due to occupational cancer in Canada: estimation using claims data from workers' compensation boards. Heal Econ Rev. 2017;7(1):9.

8. Guy GP, Yabroff KR, Ekwueme DU, Smith AW, Dowling EC, Rechis R, et al. Estimating the health and economic burden of cancer among those diagnosed as adolescents and young adults. Health Aff (Millwood). 2014; 33(6):1024-31.

9. Berger N, Savvides P, Koroukian S, Kahana E, Deimling G, Rose J, et al. Cancer in the elderly. Trans Am Clin Climatol Assoc. 2006;117:147-56.

10. Mariotto AB, Yabroff KR, Shao Y, Feuer EJ, Brown ML. Projections of the cost of cancer care in the United States: 2010-2020. J Natl Cancer Inst. 2011; 103(2):117-28 
11. Zafar SY. Financial toxicity of cancer care: it's time to intervene. J Natl Cancer Inst. 2016;108(5):djv370.

12. Gilligan AM, Alberts DS, Roe DJ, Skrepnek GH. Death or debt? National estimates of financial toxicity in persons with newly-diagnosed cancer. Am J Med. 2018;131(10):1187-99.

13. Yabroff KR, Warren JL, Brown ML. Costs of cancer care in the USA: a descriptive review. Nat Rev Clin Oncol. 2007;4:643-56.

14. Jagsi R, Pottow JA, Griffith KA, Bradley C, Hamilton AS, Graff J, et al. Longterm financial burden of breast cancer: experiences of a diverse cohort of survivors identified through population-based registries. J Clin Oncol. 2014; 32(12):1269-76.

15. Fenn KM, Evans SB, McCorkle R, DiGiovanna MP, Pusztai L, Sanft T. Impact of financial burden of cancer on survivors' quality of life. J Oncol Pract. 2014; 10(5):332-8.

16. Pisu M, Azuero A, McNees P, Burkhardt J, Benz R, Meneses K. The out of pocket cost of breast cancer survivors: a review. J Cancer Surviv. 2010;4(3):202-9.

17. Regenbogen SE, Veenstra CM, Hawley ST, Banerjee M, Ward KC, Kato I, et al. The personal financial burden of complications after colorectal cancer surgery. Cancer. 2014;120(19):3074-81.

18. Veenstra CM, Regenbogen SE, Hawley ST, Griggs JJ, Banerjee M, Kato I, et al. A composite measure of personal financial burden among patients with stage III colorectal cancer. Med Care. 2014;52(11):957-62.

19. Kent EE, Forsythe LP, Yabroff KR, Weaver KE, de Moor JS, Rodriguez JL, et al. Are survivors who report cancer-related financial problems more likely to forgo or delay medical care? Cancer. 2013;119(20):3710-7.

20. Weaver KE, Rowland JH, Bellizzi KM, Aziz NM. Forgoing medical care because of cost: assessing disparities in healthcare access among cancer survivors living in the United States. Cancer. 2010;116(14):3493-504.

21. Chino F, Peppercorn JM, Taylor DH, Ying L, Samsa G, Abernethy AP, et al. Self-reported financial burden and satisfaction with care among patients with cancer. Oncologist. 2014;19(4):414-20.

22. Sharp L, Carsin AE, Timmons A. Associations between cancer-related financial stress and strain and psychological well-being among individuals living with cancer. Psychooncology. 2013;22(4):745-55.

23. Eeckhoudt L, Gollier C, Schlesinger $H$. Changes in background risk and risk taking behavior. Econometrica. 1996;64(3):683-9.

24. Kim H, Lyons AC. No pain, no strain: impact of health on the financial security of older Americans. J Consum Aff. 2008;42(1):9-36.

25. Kim H, Yoon W, Zurlo KA. Health shocks, out-of-pocket medical expenses and consumer debt among middle-aged and older Americans. J Consum Aff. 2012;46(3):357-80.

26. Poterba JM, Venti SF, Wise DA. The asset cost of poor health. J Econ Ageing. 2017;9:172-84

27. Sheehan DF, Criss SD, Chen Y, Eckel A, Palazzo L, Tramontano AC, et al. Lung cancer costs by treatment strategy and phase of care among patients enrolled in Medicare. Cancer Med. 2019;8(1):94-103.

28. Yabroff KR, Warren JL, Schrag D, Mariotto A, Meekins A, Topot M, et al, Comparison of approaches for estimating incidence costs of care for colorectal cancer patients. Med Care. 2009;47(7):S56-63.

29. Dieguez G, Ferro C, Pyenson BS. A multi-year look at the cost burden of cancer care. In: Milliman research report. Milliman; 2017. https:/us.milliman.com/ uploadedFiles/insight/2017/cost-burden-cancer-care.pdf. Accessed 21 May 2018

30. Fireman $B H$, Quesenberry $C P$, Somkin CP, Jacobson AS, Baer D, West D, et al. Cost of care for cancer in a health maintenance organization. Health Care Financ Rev. 1997;18(4):51-76.

31. Chang S, Long SR, Kutikova L, Bowman L, Finley D, Crown WH, et al. Estimating the cost of cancer: results on the basis of claims data analyses for cancer patients diagnosed with seven types of cancer during 1999 to 2000. J Clin Oncol. 2004;22(17):3524-30.

32. Singleterry J. The costs of cancer: addressing patient costs. 2017. https:// www.fightcancer.org/policy-resources/costs-cancer. Accessed 2 Apr 2018.

33. Narang AK, Nicholas LH. Out-of-pocket spending and financial burden among Medicare beneficiaries with cancer. JAMA Oncol. 2017;3(6):757-65.

34. Yabroff KR, Lund J, Kepka D, Mariotto A. Economic burden of cancer in the United States: estimates, projections, and future research. Cancer Epidemiol Biomark Prev. 2011;20(10):2006-14

35. Jeon $\mathrm{SH}$. The long-term effects of cancer on employment and earnings. Health Econ. 2017;26(5):671-84

36. Ekwueme DU, Yabroff KR, Guy GP Jr, Banegas MP, de Moor JS, Li C, et al. Medical costs and productivity losses of cancer survivors - United States, 2008-2011. MMWR Morb Mortal Wkly Rep. 2014;63(23):505-10.
37. Sasser AC, Rousculp MD, Birnbaum HG, Oster EF, Lufkin E, Mallet D. Economic burden of osteoporosis, breast cancer, and cardiovascular disease among postmenopausal women in an employed population. Womens Health Issues. 2005;15(3):97-108.

38. Arozullah AM, Calhoun EA, Wolf M, Finley DK, Fitzner KA, Heckinger EA, et al. The financial burden of cancer: estimates from a study of insured women with breast cancer. J Support Oncol. 2004;2(3):271-8.

39. Jayadevappa R, Schwartz JS, Chhatre S, Gallo JJ, Wein AJ, Malkowicz SB. The burden of out-of-pocket and indirect costs of prostate cancer. Prostate. 2010;70(11):1255-64

40. Banegas MP, Guy GP, de Moor JS, Ekwueme DU, Virgo KS, Kent EE, et al. For working-age cancer survivors, medical debt and bankruptcy create financial hardships. Health Aff (Millwood). 2016:35:54-61.

41. Shankaran V, Jolly S, Blough D, Ramsey SD. Risk factors for financial hardship in patients receiving adjuvant chemotherapy for colon cancer: a population-based exploratory analysis. J Clin Oncol. 2012;30(14):1608-14.

42. Ramsey SD, Blough D, Kirchhoff A, Kreizenbeck K, Fedorenko C, Snell K, et al. Washington state cancer patients found to be at greater risk for bankruptcy than people without a cancer diagnosis. Health Aff (Millwood). 2013;32(6):1143-52.

43. Hackney DD, Friesner D, Johnson EH. What is the actual prevalence of medical bankruptcies? Int J Soc Econ. 2016;43(12):1284-99.

44. Irwin B, Kimmick G, Altomare I, Marcom PK, Houck K, Zafar SY, et al. Patient experience and attitudes toward addressing the cost of breast cancer care. Oncologist. 2014;19(11):1135-40.

45. Cagle JG, Carr DC, Hong S, Hong S, Zimmerman S. Financial burden among US households affected by cancer at the end of life. Psychooncology. 2016; 25(8):919-26.

46. Ell K, Xie B, Wells A, Nedjat-Haiem F, Lee P, Vourlekis B. Economic stress among low-income women with cancer. Cancer. 2008;112(3):616-25.

47. Markman M, Luce R. Impact of the cost of cancer treatment: an internetbased survey. J Oncol Pract. 2010;6(2):69-73.

48. Lee J, Kim H. An examination of the impact of health on wealth depletion in elderly individuals. J Gerontol B Psychol Sci Soc Sci. 2003;58(2):S120-6.

49. Kim H, Lee J. The impact of comorbidity on wealth changes in later life. J Gerontol B Psychol Sci Soc Sci. 2006;61(6):S307-14.

50. Spicer A, Stavrunova O, Thorp S. How portfolios evolve after retirement: evidence from Australia. Econ Rec. 2016:92(297):241-67.

51. Wu S. The effects of health events on the economic status of married couples. J Hum Resour. 2003;38(1):219-30.

52. Juster FT, Suzman R. An overview of the health and retirement study. J Hum Resour. 1995:30:S7-S56.

53. John JA, Draper NR. An alternative family of transformations. Appl Stat. 1980:29(2):190-7.

54. Gollier C, Pratt JW. Risk vulnerability and the tempering effect of background risk. Econometrica. 1996;64(5):1109-23.

55. Kimball MS. Standard risk aversion. Econometrica. 1993;61(3):589-611.

56. Rosen HS, Wu S. Portfolio choice and health status. J Financ Econ. 2004; 72(3):457-84.

57. Svynarenko R, Zhang Q, Kim H. The financial burden of cancer: financial ratio analysis. J Fam Econ Iss. 2019:40(2):165-79.

58. Blumen H, Fitch K, Polukus V. Comparison of treatment costs for breast cancer, by tumor stage and type of service. Am Health Drug Benefits. 2016;9(1):23-32.

59. Gupta A, Morrison ER, Fedorenko C, Ramsey S. Cancer diagnoses and household debt overhang. 2017. https://www.mccombs.utexas.edu/ /media/ Files/MSB/Centers/HMTF/TFF/CancerLeveragePaper.pdf. Accessed 3 Apr 2018.

60. Chino F, Peppercorn JM, Rushing C, Kamal AH, Altomare I, Samsa G, et al. Out-of-pocket costs, financial distress, and underinsurance in cancer care. JAMA Oncol. 2017;3(11):1582-4.

61. Tucker-Seeley RD, Li Y, Subramanian SV, Sorensen G. Financial hardship and mortality among older adults using the 1996-2004 health and retirement study. Ann Epidemiol. 2009:19(12):850-7.

62. Ramsey SD, Bansal A, Fedorenko CR, Blough DK, Overstreet KA, Shankaran V, et al. Financial insolvency as a risk factor for early mortality among patients with cancer. J Clin Oncol. 2016:34(9):980-6.

\section{Publisher's Note}

Springer Nature remains neutral with regard to jurisdictional claims in published maps and institutional affiliations. 